\title{
Prevalence and predictors of anemia among children under 5 years of age in Arusha District, Tanzania
}

This article was published in the following Dove Press journal: Pediatric Health, Medicine and Therapeutics

\author{
Dyness Kejo' \\ Pammla M Petrucka ${ }^{1,2}$ \\ Haikel Martin' \\ Martin E Kimanya' \\ Theobald CE Mosha ${ }^{3}$ \\ 'Department of Food Biotechnology \\ and Nutritional Sciences, Nelson \\ Mandela African Institution of \\ Science and Technology (NM-AIST), \\ Arusha, Tanzania; ${ }^{2}$ College of \\ Nursing, University of Saskatchewan \\ Saskatoon, SK, Canada; ${ }^{3}$ Department \\ of Food Technology, Nutrition \\ and Consumer Sciences, Sokoine \\ University of Agriculture, Morogoro, \\ Tanzania
}

Correspondence: Dyness Kejo Department of Food Biotechnology and Nutritional Sciences, Nelson Mandela African Institution of Science and Technology (NM-AIST), PO Box 447, Arusha, Tanzania

Email kejod@nm-aist.ac.tz

\begin{abstract}
Anemia is a global health problem affecting most developing countries. We examined the prevalence of anemia and its predictors among children under 5 years of age in Arusha District, Tanzania. Random sampling technique was used to identify 436 children aged 6-59 months. Anemia status was assessed by measuring hemoglobin concentration from blood sample obtained from a finger prick and $\mathrm{HemoCue}^{\circledR} \mathrm{Hb} 201+$ photometer. Demographic information and dietary intake data were collected using a standardized questionnaire. Anemia cut-off points were defined according to World Health Organization standards for children aged 6-59 months. Logistic regression using backward procedure was used to estimate odds ratios (ORs) at 95\% confidence intervals (CIs). Prevalence rate of anemia among under-fives was found to be $84.6 \%$ $(n=369)$. Multivariable logistic regression identified the following predictors of anemia; low birth weight (adjusted OR (AOR): 2.1, 95\% CI: 1.1-3.8), not consuming meat (AOR: $6.4,95 \%$ CI: 3.2-12.9), not consuming vegetables (AOR: 2.1, 95\% CI: 1.1-4.1), drinking milk (AOR: 2.5, 95\% CI: 1.1-5.2), and drinking tea (AOR: 4.5, 95\% CI: $1.5-13.7$ ). It was concluded that low birth weight and dietary factors (ie, low or nonconsumption of iron-rich foods like meat, vegetables, and fruits) were predictors of anemia among under-five children living in this rural setting. Community education on exclusive breastfeeding and introduction of complementary foods should be improved. Mothers and caretakers should be educated about nutrition, in general, as well as potential use of micronutrient powder to improve the nutritional quality of complementary foods.
\end{abstract}

Keywords: anemia, low birth weight, dietary intake, predictors, under-five children

\section{Introduction}

Childhood anemia is a condition where a child has an insufficient hemoglobin $(\mathrm{Hb})$ level to provide adequate oxygen to the body tissues. For children between 6 and 59 months (generally referred to as under-fives), the threshold $\mathrm{Hb}$ level for being nonanemic is 11.0 grams per deciliter (g/dL). ${ }^{1}$ Anemia has numerous potential etiologies. Followed by acute blood loss and heredity or acquired diseases, the most common cause of anemia in young children is low consumption and absorption of iron-rich foods (ie, meat and meat products). ${ }^{2-5}$ These conditions most often lead to iron deficiency anemia, which accounts for approximately half of all anemia cases globally, with under-five children and women being the most affected. ${ }^{6,7}$ Although relevant across the life span, anemia in under-five children is a special case given its significance to underpinning a range of morbidities and mortality within this population subset. ${ }^{8}$ Not only are these patterns concerning due to their highly preventable and treatable nature, but they also project submit your manuscript | www.dovepress.com 
potential long-term individual and social consequences. At the individual level, childhood anemia contributes to poor motor and cognitive development, poor school performance, as well as increased morbidity and mortality., ${ }^{90}$ At the societal level, there are strong indicators that anemia impacts on the socioeconomic well-being and productivity of a country. ${ }^{11}$ Globally, data indicate that $43 \%$ of under-five children were anemic in 2011, with prevalence in the developing world, specifically South Asia and East Africa, being 58\% and $55 \%$, respectively. ${ }^{12}$ Generally, there is high variability in the reported prevalence of anemia across the continent of Africa. A number of reports ${ }^{13-15}$ suggested rates ranging between $71 \%$ and $79 \%$ in Kenya, South Africa, and Tanzania. According to the Tanzania Demographic and Health Survey 2015 (TDHS), 58\% of children under the age of 5 years in Tanzania were anemic. A recent study in Mwanza, Tanzania reported a prevalence rate of anemia at $77.2 \%$ (with mild, moderate, and severe anemia being reported in $16.5 \%, 33 \%$, and $27.7 \%$, respectively). ${ }^{16}$

Pregnant and lactating women and under-five children are the most vulnerable social groups to micronutrient deficiencies due to their increased needs for vitamins and minerals. ${ }^{17}$ Along with this greater need comes a higher consequence due to lesser reserves. The literature is replete with nutrition interventions, ${ }^{8}$ which clearly reveal the "one-off," crosssectional nature of most interventions. Stoltzfus ${ }^{18}$ indicated that effectiveness of such interventions has been inconsistently demonstrated, leading to difficulties in scaling up.

Given the significantly high levels of anemic underfive children in Tanzania, there is strong need for action. In order to design and deliver effective interventions, it is important to know the strong risk factors for predicting anemia among under-five children. The intent of this study was to first affirm the baseline prevalence rates of anemia in under-five children in selected wards of the predominantly periurban/rural Arusha District prior to implementation of an intervention to address anemia among the under-five children. Consideration of factors contributing to anemia among under-five children in the specific locations would be essential in order to ensure effectiveness of the proposed intervention.

\section{Materials and methods}

\section{Study site}

This community-based cross-sectional study was conducted in Arusha Rural District, Tanzania. This District is primarily rural, shares similar socioeconomic patterns with most of the rural districts in Tanzania, demonstrates cultural diversity, and reports childhood anemia prevalence similar to or above national levels. ${ }^{19}$ Within the district, there are 20 wards, each having at least one reproductive and child health $(\mathrm{RCH})$ clinic for mothers and children. Of these, three wards - Oldonyosambu, Oturumeti, and Seliani - were randomly selected for the study.

\section{Subject inclusion criteria}

Inclusion criteria used for subjects' selection included family residence within the study villages, child(ren) between 6 and 59 months attending a designated outpatient $\mathrm{RCH}$ clinic, child(ren) consuming some solid foods (ie, no longer exclusively breastfeeding). Exclusion criteria included child(ren) aged above 60 months, having sickle-cell anemia or currently consuming multivitamin and/or mineral supplements on a regular basis, or the family rejecting participation in the study.

\section{Sampling procedure}

The sampling frame was established, and 20 wards with heath facilities offering RCH clinic services were identified and coded from 01 to 20 . Three wards out of 20 wards were randomly selected by using a table of random numbers. In the selected wards, parents/guardians with children aged 6-59 months were invited to the selected health facilities for free anemia screening and nutritional status assessment. Children who met the inclusion criteria were selected for the study. A total of 127, 159, and 150 children from Oturumeti, Oldonyosambu, and Seliani, respectively, were selected for the study.

\section{Sample size}

A sample size was determined using the statistical power analysis formula $\mathrm{n}=\mathrm{z}^{2} \mathrm{p}(1-\mathrm{p}) / \mathrm{d}^{2},{ }^{20}$ where $\mathrm{n}=$ sample size, $\mathrm{p}=$ prevalence of anemia $(60 \%)$ (TDHS, 2010), $\mathrm{z}=\mathrm{z}$-value at $95 \%$ confidence $(=1.96), \mathrm{d}=$ level of significance $(=5 \%)$, with an anticipated attrition of $18 \%$ to follow-up yielded a total of 436 mother-child pairs.

\section{Anemia screening}

At each RCH clinic, children were screened for anemia using the HemoCue (HemoCue ${ }^{\circledR} \mathrm{Hb} 201+$ ) photometer. Safety lancets were used to obtain the finger prick blood, which was collected in the microcuvettes. Alcohol swabs were used to clean the fingers before pricking. The first drop of blood was wiped off with a cotton wool, while the second 
drop was collected using a microcuvette. The blood sample in the microcuvette was loaded in the calibrated HemoCue ${ }^{\circledR}$ photometer and $\mathrm{Hb}$ concentration read to the nearest $0.1 \mathrm{~g} / \mathrm{dL}$. Children with $\mathrm{Hb}$ level $<11 \mathrm{~g} / \mathrm{dL}$ were considered anemic, and graded as mild (10-10.9 g/dL), moderate (7-9.9 g/dL), and severe $(<7 \mathrm{~g} / \mathrm{dL}){ }^{21}$

Data on a range of socioeconomic, demographic, and childhood-related illnesses were captured using a structured pretested, standard questionnaire at baseline during face-toface interviews with the parents/guardians. Key elements were: 1) child-information - gender, age, birth weight, feeding practices, and illness 2 weeks prior to survey; and 2) family-specific - socioeconomic and demographic characteristics of parents/family, including education level, marital status, occupation, and ownership of animals and land. This information was critical for determining risk factors for anemia among children and would be essential in planning, implementation, and evaluation of intervention programs for controlling childhood anemia.

\section{Data analysis}

Analysis of data was done using the Statistical Package for Social Sciences $^{\mathrm{TM}}$ (Version 20.0; IBM Corp., Armonk, NY, USA). Frequency, means, and standard deviations were used to describe the characteristics of the study population and to estimate the prevalence of anemia. $\chi^{2}$ tests were used to compare group differences for categorical variables. Univariate logistic regression was performed, and all variables having a $p<0.05$ were included in multivariate logistic regression model. Using a backward elimination method, a stepwise regression was done to progressively exclude independent variables which had no effect when put together. Association between dependent and independent variables was assessed using odds ratios (OR) at 95\% confidence interval (CI).

\section{Ethical considerations}

Ethical clearance was obtained from the National Institute for Medical Research, Tanzania. Permission was also obtained from the regional and district health offices in Arusha to conduct the study in the $\mathrm{RCH}$ clinics. The purpose of the study was explained to all mothers/guardians of the children, and those who agreed to participate signed an informed consent to affirm their willingness to participate. After screening for anemia, results were shared and discussed with parent(s)/ guardian(s). Children found to be severely anemic $(\mathrm{Hb}$ $<7.0 \mathrm{~g} / \mathrm{dL}$ ) were referred to the medical doctor for treatment because severe anemia usually needs immediate medical attention to treat the underlying causes and restore the normal levels of red blood cells; hence, they were excluded from the intervention aspects of this study.

\section{Results}

A total of 436 children aged 6-59 months participated in the study. The mean age of participating children was $20.3 \pm 10.8$ months. About 85\% $(\mathrm{n}=369)$ had anemia $(\mathrm{Hb}<11 \mathrm{~g} / \mathrm{dL})$ with no significant difference in terms of gender (ie, $81.4 \%$ females; $87.2 \%$ males). Younger children (under 2 years) were more likely to be anemic compared to their older peers (Table 1).

Table I Children's characteristics in relation to anemia status

\begin{tabular}{|c|c|c|c|}
\hline Variables & $\begin{array}{l}\text { Subjects } \\
\text { (n) }\end{array}$ & $\begin{array}{l}\% \text { with } \\
\text { anemia }\end{array}$ & $p$-value \\
\hline \multicolumn{4}{|l|}{ Gender } \\
\hline Female & 194 & 81.4 & 0.09 \\
\hline Male & 242 & 87.2 & \\
\hline \multicolumn{4}{|l|}{ Age (months) } \\
\hline $6-11$ & 116 & 86.2 & 0.9 \\
\hline $12-23$ & 163 & 85.3 & \\
\hline $24-35$ & 108 & 83.3 & \\
\hline $36-59$ & 49 & 81.6 & \\
\hline \multicolumn{4}{|l|}{ Morbidity } \\
\hline Not ill & 142 & 82.4 & 0.3 \\
\hline With illness & 294 & 85.7 & \\
\hline \multicolumn{4}{|l|}{ Type of disease ${ }^{a}$} \\
\hline Diarrhea & 66 & 84.8 & 0.07 \\
\hline Fever & 51 & 74.5 & \\
\hline Cough & 25 & 92 & \\
\hline Multiple diseases & 150 & 88.7 & \\
\hline \multicolumn{4}{|l|}{ Exclusively breastfed status } \\
\hline Yes & 70 & 80.0 & 0.2 \\
\hline No & 366 & 85.5 & \\
\hline \multicolumn{4}{|l|}{ Birth weight } \\
\hline Normal weight (>2.5kg) & 224 & 79.0 & $0.00 *$ \\
\hline Low birth weight $(<2.5 \mathrm{~kg})$ & 212 & 90.6 & \\
\hline \multicolumn{4}{|c|}{ Occupation of the household head } \\
\hline Employed & 50 & 96 & $0.02 *$ \\
\hline Farmer & 247 & 81.4 & \\
\hline Pastoralist & 76 & 90.8 & \\
\hline Self-employed & 63 & 81 & \\
\hline \multicolumn{4}{|l|}{ Marital status of mother } \\
\hline Single & 44 & 90.9 & 0.2 \\
\hline Married & 392 & 83.9 & \\
\hline \multicolumn{4}{|l|}{ Mother's age (years) } \\
\hline $15-24$ & 213 & 86.9 & 0.4 \\
\hline $25-34$ & 197 & 82.2 & \\
\hline Above 34 & 26 & 84.6 & \\
\hline \multicolumn{4}{|l|}{ Residence (community names) } \\
\hline Oldonyosambu & 159 & 76.1 & $<0.001 *$ \\
\hline Seliani & 150 & 86.7 & \\
\hline Oturumeti & 127 & 92.9 & \\
\hline
\end{tabular}

Notes: Multiple response if the child had two or more diseases (diarrhea, fever, or cough); ${ }^{*} p<0.05$. 


\section{Association of anemia and feeding practice}

Table 2 shows the feeding habits that were associated with anemia. Only $12.6 \%(\mathrm{n}=55)$ of the children consumed meat, while merely $1.8 \%(\mathrm{n}=8)$ consumed fruits. These numbers likely reflect a lack of nutrition knowledge on the part of the mothers. Most complementary foods were plant based. The main foods given to the children were thin plain maize porridge and composite flour porridge. The composite flour was obtained from a mixture of finger millet, rice, peanuts, and sardines.

\section{Anemia and associated risk factors}

Table 3 summarizes factors associated with anemia. Five factors were significantly associated with anemia among the under-five children. These factors were: low birth weight, nonconsumption of meat, vegetables, fruits, and drinking tea with sugar. In multivariate analysis, the following factors remained as independent risk factors associated with anemia: having low birth weight (adjusted odds ratio (AOR): 2.1, 95\%

Table 2 Association of anemia and feeding habits

\begin{tabular}{|c|c|c|c|}
\hline Variable & $\begin{array}{l}\text { Subjects } \\
\text { (n) }\end{array}$ & $\begin{array}{l}\text { \% with } \\
\text { anemia }\end{array}$ & p-value \\
\hline \multicolumn{4}{|l|}{ Meat } \\
\hline Consumed & 55 & 50.9 & $0.00^{*}$ \\
\hline Not consumed & 381 & 89.5 & \\
\hline \multicolumn{4}{|l|}{ Beans } \\
\hline Consumed & 380 & 83.6 & 0.2 \\
\hline Not consumed & 56 & 90.5 & \\
\hline \multicolumn{4}{|l|}{ Milk } \\
\hline Consumed & 377 & 86.4 & 0.09 \\
\hline Not consumed & 56 & 73.3 & \\
\hline \multicolumn{4}{|l|}{ Vegetable } \\
\hline Consumed & 261 & 80.5 & $0.00 *$ \\
\hline Not consumed & 175 & 90.9 & \\
\hline \multicolumn{4}{|l|}{ Fruits } \\
\hline Consumed & 8 & 37.5 & $0.00^{*}$ \\
\hline Not consumed & 428 & 88.5 & \\
\hline \multicolumn{4}{|l|}{ Loshoro $^{a}$} \\
\hline Consumed & 346 & 84.4 & 0.7 \\
\hline Not consumed & 90 & 85.6 & \\
\hline \multicolumn{4}{|l|}{ Kideri $^{\mathrm{b}}$} \\
\hline Consumed & 365 & 84.9 & 0.8 \\
\hline Not consumed & 71 & 83.0 & \\
\hline \multicolumn{4}{|l|}{ Composite porridge } \\
\hline Consumed & 284 & 84.2 & 0.7 \\
\hline Not consumed & 152 & 85.5 & \\
\hline \multicolumn{4}{|l|}{ Tea with sugar } \\
\hline Do not drink & 21 & 52.4 & $0.00 *$ \\
\hline Drink & 415 & 86.3 & \\
\hline
\end{tabular}

Notes: ${ }^{\mathrm{L}}$ Local foods cooked from maize and with mixed sour milk; ${ }^{\mathrm{b}}$ mashed banana mixed with sour milk; ${ }^{*} p<0.05$.
CI: 1.1-3.8) nonconsumption of meat (AOR: 6.4, 95\% CI: 3.2-12.9), nonconsumption of vegetable (AOR: 2.1, 95\% CI: 1.1-4.1), drinking milk (AOR: $2.5,95 \%$ CI: 1.1-5.2), and drinking tea with sugar (AOR: 4.5, 95\% CI: 1.5-13.7).

\section{Discussion}

This community-based cross-sectional study documented the prevalence and determinants of anemia in three wards of Arusha District, Tanzania. It was revealed that the prevalence rate of anemia was $84.6 \%$, which was higher than the regional (57\%) and Tanzanian (58\%) prevalence rates. ${ }^{19}$ The current findings were similar to a previous study in Mwanza, which showed a $77.2 \%$ prevalence rate of anemia. ${ }^{16}$ The observed high prevalence could be due to deficiency in iron nutritives among under-five children associated with poor food availability, cultural behaviors (which are not necessarily evidence informed and may contribute to nutritional deficits), and maternal factors such as employment. ${ }^{16}$ Mothers used thin gruel prepared from cereal (maize, rice, millet, or sorghum) as a major complementary food for their children. This finding mirrors results from other studies in Tanzania. ${ }^{22-25}$ Mothers used thin maize porridge due to early introduction of complementary foods. Most mothers also did not follow internationally recommended practices, which require exclusive breastfeeding up to 6 months ${ }^{25,26}$ possibly due to lack of nutritional education and other sociodemographic conditions. ${ }^{16}$

Our study revealed that children below 2 years were more likely to be anemic compared to the older children. This concurred with prior findings showing that at the younger age, there is high demand for nutrients to support the rapid body growth of children, ${ }^{27}$ which further increases their need for iron. Complementary foods are started when the children reach 6 months, if nutritionally poor complementary foods were introduced children were more likely to be anemic. ${ }^{28}$ Children above 2 years are able to eat more variety of foods, which put them at less risk of being anemic. ${ }^{29}$

In our study, about $84 \%$ of children were not exclusively breastfed. This practice led to the early introduction of complementary foods, which are often of low quality and insufficient quantity. Frequently reported complementary foods included thin plain maize porridge and cow's milk, which are poor sources of iron. Consumption of cow's milk has a negative influence on iron status as it reduces bioavailability of iron provided by other foods and has been shown to have a negative effect on nonheme and heme iron absorption. ${ }^{21,27,30-35}$ Addition of cow's milk in complementary foods is not problematic, (foods like Loshoro and Kideri), 
Table 3 Determinants of childhood anemia

\begin{tabular}{|c|c|c|c|c|c|c|}
\hline Variable & $\mathbf{N}$ & Anemia (\%) & COR & $p$-value & AOR & $p$-value \\
\hline \multicolumn{7}{|l|}{ Birth weight } \\
\hline Normal (>2.5 kg) & 224 & 79.0 & I & & 1 & \\
\hline Low $(<2.5$ kg) & 212 & 90.6 & $2.5(1.5-4.5)$ & $0.01 *$ & $2.1(1.1-3.8)$ & $0.02^{*}$ \\
\hline \multicolumn{7}{|l|}{ Child age } \\
\hline Less than 2 years & 291 & 84.5 & I & & 1 & \\
\hline Above 2 years & 145 & 84.8 & $1.0(0.6-1.8)$ & 0.9 & $1.4(0.7-2.9)$ & 0.4 \\
\hline \multicolumn{7}{|l|}{ Meat } \\
\hline Consumed & 55 & 50.9 & I & & 1 & \\
\hline Not consumed & 381 & 89.5 & $8.2(4-15)$ & $<0.00 I^{*}$ & $6.4(3.2-12.9)$ & $<0.00 I^{*}$ \\
\hline \multicolumn{7}{|l|}{ Beans } \\
\hline Consumed & 380 & 83.6 & I & & & \\
\hline Not consumed & 56 & 90.5 & $1.9(0.8-4.5)$ & 0.2 & & \\
\hline \multicolumn{7}{|l|}{ Milk } \\
\hline Not consumed & 56 & 73.3 & 1 & & I & \\
\hline Consumed & 377 & 86.4 & $2.3(1.2-4.4)$ & $0.01 *$ & $2.5(I . I-5.2)$ & $0.02^{*}$ \\
\hline \multicolumn{7}{|l|}{ Vegetable } \\
\hline Consumed & 261 & 80.5 & 1 & & 1 & \\
\hline Not consumed & 175 & 90.9 & $2.4(1.3-4.4)$ & $<0.00 I^{*}$ & $2.1(1.1-4.1)$ & $0.03^{*}$ \\
\hline \multicolumn{7}{|l|}{ Fruits } \\
\hline Consumed & 8 & 37.5 & 1 & & 1 & \\
\hline Not consumed & 428 & 85.5 & $9.8(2.3-42.2)$ & $<0.001$ & $2.8(0.5-14)$ & 0.2 \\
\hline \multicolumn{7}{|l|}{ Tea with sugar } \\
\hline Do not drink & 21 & 52.4 & 1 & & I & \\
\hline Drink & 415 & 86.3 & $5.7(2.3-14.0)$ & $<0.00 I^{*}$ & $4.5(1.5-13.7)$ & $<0.00 I^{*}$ \\
\hline \multicolumn{7}{|l|}{ Residence } \\
\hline Oldonyosambu & 159 & 76.1 & 1 & & 1 & \\
\hline Seliani & 150 & 86.7 & $2.0(1.1-3.7)$ & $0.02 *$ & $1.6(0.8-3.3)$ & 0.2 \\
\hline Oturumeti & 127 & 92.3 & $4.1(1.9-8.9)$ & $0.00 *$ & $2.2(0.9-5.2)$ & 0.06 \\
\hline
\end{tabular}

Notes: Variables in the model were controlled for gender and age of the children; ${ }^{*} p<0.05$.

Abbreviations: AOR, adjusted odds ratio; COR, crude odds ratio.

but it should not be used as the main meal before 12 months and should not replace iron-rich foods. ${ }^{21}$ In the current study, consumption of cow's milk was found to be a risk factor for childhood anemia. ${ }^{21,27,32-35}$

Drinking tea with sugar was found to increase the risk of childhood anemia in this study. According to Nelson and Poulter $^{39}$ and El Kishawi et al, ${ }^{29}$ tea contains polyphenols which bind iron to form an insoluble complex which cannot be absorbed. Polyphenol in tea binds to iron and form nonhydrolyzable complexes which are then excreted in the feces. ${ }^{36}$ Tea given with meals should be discouraged as this reduces the bioavailability of iron in the food. Other authors have reported significant association of anemia with intake of tea and other meals. . $^{31,37-39}$

The World Health Organization ${ }^{40}$ reported that it is impossible to supply enough iron from unmodified plant-based complementary foods to meet the recommended daily intake of iron for under-fives without adding animal products such as liver, fish, beef, and eggs. Apart from other causes of anemia like blood loss, diseases, vitamin A, and folate deficiency, ${ }^{41}$ multivariate analysis revealed that, in our population, poor feeding practices especially nonconsumption of iron-rich foods (ie, meat, vegetables, and fruits) were significantly associated with the presence of childhood anemia. Meat and/or meat-containing infant foods were rarely $(12.6 \%)$ consumed by the study subjects. This finding reflected the previously reported challenge in Tanzania, in which many households could not afford animal products (ie, high iron content foods). Consumption of plant-based products (low iron content foods) was the only alternative. ${ }^{23-25}$ The quality of complementary foods was significantly associated with anemia in the present study. For example, consumption of vegetables and fruits was associated with reduced rates of anemia. Further, almost $98 \%(n=428)$ of study children did not eat fruits, which may have contributed to the higher prevalence rate of anemia. Vitamin $\mathrm{C}$, which originates from fruits, potentiates absorption of nonheme iron that is found in legumes and other plant-based meals. ${ }^{42}$

According to the World Health Organization ${ }^{1}$ guidelines, MNP which is a single-dose packet of powder containing 
iron, vitamin A, zinc, and other vitamins and minerals, can be sprinkled onto any semisolid food at home or at any other point of use to increase the content of essential nutrients in the infant's diet during this period. This is done without changing the usual baby diet.

We observed low birth weight as a significant risk factor for anemia in children, in line with previous findings. ${ }^{24,43}$ Although it is known that low birth weight is strongly associated with maternal anemia, which negatively impacts the iron store of the child at birth, we did not explore this factor in our study. ${ }^{44,45}$

Overall high prevalence rate of anemia among the under-five children was associated with early introduction of nutritionally poor complementary foods and lack of exclusive breastfeeding for the first 6 months of life. Introduction of nutritious complementary foods, such as iron-fortified cereals and meat/meat products, could have highly reduced the prevalence rate of anemia among the children.

\section{Limitations}

One of the limitations of this study that may have affected the results is the cross-sectional nature of the study that precludes identifying seasonal patterns. At the time of the study, it was the dry season, which may have also contributed to higher levels of childhood anemia and lower levels of consumption patterns of unavailable/expensive foods.

Another limitation of note may relate to the 'illness status' of the children. Although the children were outpatient visitors to the RCHs for regular measurements (physiological and anthropometric), many reported an illness in the 14 days prior to their visit. It is recognized that illnesses or treatments of such illnesses (ie, medications for infection, malaria) may in fact cause a mild anemia. ${ }^{46,47}$ Hence, a future study may control for such confounding factors.

\section{Conclusion}

The findings of this study affirmed the high prevalence rate of anemia among under-five children in Arusha District which was higher than the previous rate reported by NBS and MACRO. ${ }^{19}$ It was found that best predictors for anemia among under-five children living in a rural setting were low birth weight and dietary factors (specifically nonconsumption of iron-rich foods like meat, vegetables, and fruits). It was recommended based on this study that community nutrition education, especially on exclusive breastfeeding and introduction of complementary foods, should be improved. Additionally, it is strongly suggested that a multisite, multiyear study be conducted to allow a deeper understanding of the causes and factors most impacting on under-five anemia in Tanzania.

\section{Acknowledgment}

This study was funded by the Government of Tanzania through the Commission for Science and Technology (COSTECH).

\section{Disclosure}

The authors report no conflicts of interest in this work.

\section{References}

1. WHO. Haemoglobin concentrations for the diagnosis of anaemia and assessment of severity. Vitamin and Mineral Nutrition Information System. Geneva: World Health Organization; 2011.

2. Black RE, Victora CG, Walker SP, et al. Maternal and child undernutrition and overweight in low-income and middle-income countries. Lancet. 2013;382(9890):427-451.

3. Bhutta ZA, Salam RA, Das JK. Meeting the challenges of micronutrient malnutrition in the developing world. Br Med Bull. 2013;106(1):7-17.

4. Cardoso MA, Scopel KK, Muniz PT, Villamor E, Ferreira MU. Underlying factors associated with anemia in Amazonian children: a population-based, cross-sectional study. PLoS One. 2012;7(5):e36341.

5. Yang W, Li X, Li Y, et al. Anemia, malnutrition and their correlations with socio-demographic characteristics and feeding practices among infants aged $0-18$ months in rural areas of Shaanxi province in northwestern China: a cross-sectional study. BMC Public Health. 2012;12(1):1.

6. Schrier SL. Causes and Diagnosis of Iron Deficiency Anemia in the Adult. In: UpToDate, Waltham, MA: Wolters Kluwer Health; 2017. Accessed February 20, 2017.

7. de Benoist B, McLean E, Egli I, Cogswell M. Worldwide Prevalence of Anaemia 1993-2005: WHO Global Database on Anaemia. Geneva: World Health Organization; 2008.

8. Allen LH, De Benoist B, Dary O, Hurrell R, World Health Organization. Guidelines on Food Fortification with Micronutrients. Geneva: World Health Organization; 2006.

9. Kounnavong S, Sunahara T, Mascie-Taylor C, et al. Effect of daily versus weekly home fortification with multiple micronutrient powder on haemoglobin concentration of young children in a rural area, Lao People's Democratic Republic: a randomised trial. Nutr J. 2011;10(129).

10. Development Partners Group on Nutrition. Investing in Nutrition for National Growth and Prosperity in Tanzania; 2010. Available from: https://www.google.ca/search?q=DPG.+Investing+in+Nutrition+fo$\mathrm{r}+$ National + Growth + and + Prosperity + in + Tanzania $\% 3 B+2010 \& i e=u t$ f- $8 \&$ oe $=$ utf- $8 \&$ client $=$ firefox-b\&gfe_rd $=$ cr\&dcr $=0 \&$ ei $=$ tTBNWuqPG PTe8AfT14zwBg. Accessed January 3, 2018.

11. Tulchinsky TH. Micronutrient deficiency conditions: global health issues. Public Health Rev. 2010;32(1):243-255.

12. Stevens GA, Finucane MM, De-Regil LM, et al. Global, regional, and national trends in haemoglobin concentration and prevalence of total and severe anaemia in children and pregnant and non-pregnant women for 1995-2011: a systematic analysis of population-representative data. Lancet Global Health. 2013;1(1):e16-e25.

13. Foote EM, Sullivan KM, Ruth LJ, et al. Determinants of anemia among preschool children in rural, western Kenya. Am JTropical Med Hygiene. 2013;88(4):757-764.

14. Heckman J, Samie A, Bessong P, et al. Anaemia among clinically well under-fives attending a community health centre in Venda, Limpopo Province. S Afr Med J. 2010;100(7):445-448.

15. Magesa A, Magesa P. Association between anaemia and infections (HIV, malaria and hookworm) among children admitted at Muhimbili National Hospital. East Afr J Public Health. 2012;9(3):96-100.

16. Simbauranga RH, Kamugisha E, Hokororo A, Kidenya BR, Makani J. Prevalence and factors associated with severe anaemia amongst under-five children hospitalized at Bugando Medical Centre, Mwanza, Tanzania. BMC Hematol. 2015;15(1):1. 
17. Arimond M, Wiesmann D, Becquey E, et al. Simple food group diversity indicators predict micronutrient adequacy of women's diets in 5 diverse, resource-poor settings. J Nutr. 2010;140(11):2059S-2069S.

18. Stoltzfus RJ. Summary: implications for research and programs. J Nutr. 2001;131(2):697S-701S.

19. NBS, MACRO. Tanzania Demographic and Health Survey. Preliminary Findings. DHS Dar es Salaam: National Bureau of Statistics, Dar es Salaam, Tanzania \& Macro; 2015.

20. Burger SE, Pierre-Louis JN. How to Assess Iron Deficiency Anemia and Use the HemoCue. New York: Hellen Keller International; 2002.

21. Hallberg L, Rossander-Hultén L, Brune M, Gleerup A. Bioavailability in man of iron in human milk and cow's milk in relation to their calcium contents. Pediatr Res. 1992;31(5):524-527.

22. Kimanya ME, De Meulenaer B, Tiisekwa B, et al. Fumonisins exposure from freshly harvested and stored maize and its relationship with traditional agronomic practices in Rombo district, Tanzania. Food Addit Contam. 2009;26(8):1199-1208.

23. Nyaruhucha C, Msuya J, Mamiro P, Kerengi A. Nutritional status and feeding practices of under-five children in Simanjiro District, Tanzania Tanzania J Health Res. 2006;8(3):162.

24. Mamiro PS, Kolsteren P, Roberfroid D, Tatala S, Opsomer AS, Van Camp JH. Feeding practices and factors contributing to wasting, stunting, and iron-deficiency anaemia among 3-23-month old children in Kilosa district, rural Tanzania. J Health Popul Nutr. 2005;23(3):222-230.

25. Kulwa KB, Kinabo JL, Modest B. Constraints on good child-care practices and nutritional status in urban Dar-es-Salaam, Tanzania. Food Nutr Bull. 2006;27(3):236-244.

26. Kimiywe J, Chege P. Complementary feeding practices and nutritional status of children 6-23 months in Kitui County, Kenya. J Appl Biosci. 2015;85(1):7881-7890.

27. Adu-Afarwuah S, Lartey A, Brown KH, Zlotkin S, Briend A, Dewey $\mathrm{KG}$. Home fortification of complementary foods with micronutrient supplements is well accepted and has positive effects on infant iron status in Ghana. Am J Clin Nutr. 2008;87(4):929-938.

28. Tatala S, Svanberg U, Mduma B. Low dietary iron availability is a major cause of anemia: a nutrition survey in the Lindi District of Tanzania. Am J Clin Nutr. 1998;68(1):171-178.

29. El Kishawi RR, Soo KL, Abed YA, Muda WAMW. Anemia among children aged $2-5$ years in the Gaza Strip-Palestinian: a cross sectional study. BMC Public Health. 2015;15(1):1.

30. Levy-Costa RB, Monteiro CA. Cow's milk consumption and childhood anemia in the city of São Paulo, southern Brazil. Rev Saúde Pública. 2004;38(6):797-803.
31. Wilson C, Grant C, Wall C. Iron deficiency anaemia and adverse dietary habits in hospitalised children. $N Z$ Med J. 1999;112(1089): 203-206.

32. Hurrell R, Egli I. Iron bioavailability and dietary reference values. $A m$ J Clin Nutr. 2010;91(5):1461S-1467S.

33. Silva DG, Priore SE, Franceschini Sdo C. Risk factors for anemia in infants assisted by public health services: the importance of feeding practices and iron supplementation. J Pediatr. 2007;83(2):149-156.

34. Persson LA, Haschke F, Nestlé S. The Euro-Growth Iron Study Group. Prevalence of iron deficiency in 12-mo-old infants from 11 European areas and influence of dietary factors on iron status (Euro-Growth study) Acta Pñdiatr. 2001;90:492-498.

35. Vanderhoof JA, Kleinman RE. Iron requirements for infants with cow milk protein allergy. J Pediatr. 2015;167(4):S36-S39.

36. Ma Q, Kim EY, Lindsay EA, Han O. Bioactive dietary polyphenols inhibit heme iron absorption in a dose-dependent manner in human intestinal Caco-2 cells. J Food Sci. 2011;76(5):H143-H150.

37. Merhav H, Amitai Y, Palti H, Godfrey S. Tea drinking and microcytic anemia in infants. Am J Clin Nutr. 1985;41(6):1210-1213.

38. Zaida F, Bureau F, Guyot S, et al. Iron availability and consumption of tea, vervain and mint during weaning in Morocco. Ann Nutr Metab. 2006;50(3):237-241.

39. Nelson M, Poulter J. Impact of tea drinking on iron status in the UK: a review. J Hum Nutr Diet. 2004;17(1):43-54.

40. Dop MC, Benbouzid D, Trèche S, de Benoist B, Verster A, Delpeuch F. Complementary Feeding of Young Children in Africa and the Middle East. Geneva: World Health Organization; 1999:43-58.

41. Olivares M, Walter T, Hertrampf E, Pizarro F. Anaemia and iron deficiency disease in children. Br Med Bull. 1999;55(3):534-543.

42. Amsalu S, Tigabu Z. Risk factors for ever acute malnutrition in children under the age of five: a case-control study. Ethiop J Health Dev. 2008;22(1): 21-25.

43. Kalanda BF, Verhoeff FH, Brabin B. Breast and complementary feeding practices in relation to morbidity and growth in Malawian infants. Eur J Clin Nutr. 2006;60(3):401-407.

44. Kidanto HL, Mogren I, Lindmark G, Massawe S, Nystrom L. Risks for preterm delivery and low birth weight are independently increased by severity of maternal anaemia. SAMJ. 2009;99(2):98-102.

45. Haggaz AD, Radi EA, Adam I. Anaemia and low birthweight in western Sudan. Trans R Soc Trop Med Hyg. 2010;104(3):234-236.

46. Beutler E. G6PD deficiency. Blood. 1994;84(11):3613-3636.

47. Beutler E. Glucose-6-phosphate dehydrogenase deficiency: a historical perspective. Blood. 2008;111(1):16-24.
Pediatric Health, Medicine and Therapeutics

\section{Publish your work in this journal}

Pediatric Health, Medicine and Therapeutics is an international, peerreviewed, open access journal publishing original research, reports, editorials, reviews and commentaries. All aspects of health maintenance, preventative measures and disease treatment interventions are addressed within the journal. Practitioners from all disciplines are invited to submit
Dovepress

their work as well as healthcare researchers and patient support groups. The manuscript management system is completely online and includes a very quick and fair peer-review system. Visit http://www.dovepress.com/ testimonials.php to read real quotes from published authors. 